\title{
Design \& Development Analysis of Aircraft Composite Window Frame
}

\author{
G.Veranna ${ }^{1}$,B. Shiva prasad ${ }^{2}$ ch.Neeraja ${ }^{3}$, \\ 1,2,3 (Assistant professor, Mechanical Department, CMRTC/ JNTUH, India)
}

\begin{abstract}
In most manufactured and operated aircraft used frames of Windows, made of aluminum, for production of which uses the processes of stamping, extrusion and further processing under size. The frame of the window consists of the following main parts: outer flange, an inner flange and a vertical flange placed between these flanges perpendicular thereto. Upon aluminum we use composites as a material in making window frame, the weight of the frame made in the above way, is near approximately 50 percent of the weight of conventional aluminum frame windows. Moreover, the cost of production in both cases about the same. It is assumed that the tolerances of such frame in industrial production will be significantly less than the tolerances of the respective aluminum products. At the same time. It is assumed that proposed in the invention, the frame of the window will provide enhanced security and improved thermal insulation compared to conventional aluminum frames. The testing of these frames is done under researchers who worked under defense. This main project report addresses the Design, Development and testing of window frame.
\end{abstract}

Keywords: Composite material of E-glass fabric, Aircraft window Frame, cad design mould for FRP, fabrication of aircraft window frame, Vibration test and tensile test.

\section{Introduction}

The present invention relates generally to aircraft, and, more specifically, to windows therein. In the typical commercial aircraft, numerous windows are distributed along both sides of the fuselage from the cockpit aft to just before the tail.. Typical aircraft skins are made of high strength metal, such as aluminum, and the typical window frame is also made of high strength metal. In most of the passenger aircraft manufactured and in operation today, window frames made of aluminum are used, which comprise a part which is made by forging and truing.. Aircraft weight directly affects aircraft efficiency during flight, and aircraft are therefore being continually developed for reducing weight while providing sufficient strength of the various aircraft components for enjoying long service life during commercial operation. Furthermore, the cost of commercial aircraft operation is a paramount design objective especially with the ever increasing price of engine fuel. The initial manufacturing cost of the aircraft itself is also an important design objective, with both the cost of the initial aircraft purchase and subsequent cost of operation being significant criteria in the competitive evaluation of aircraft and their expected low cost operation during the service life .Accordingly, it is desired to provide an improved aircraft window frame, and method of its manufacture.

\section{Composite Material}

In its most basic form a composite material is one, which is composed of at least two elements working together to produce material properties that are different to the properties of those elements on their own. In practice, most composites consist of a bulk material (the "matrix"), and a reinforcement of some kind, added primarily to increase the strength and stiffness of the matrix.

\subsection{Role of matrix in a composite}

Many materials when they are in a fibrous form exhibit very good strength property but to achieve these properties the fibers should be bonded by a suitable matrix..

\subsection{Materials used as matrices in composites}

In its most basic form a composite material is one, which is composed of at least two elements working together to produce material properties that are different to the properties of those elements on their own. In practice, most composites consist of a bulk material (the matrix) and a reinforcement of some kind, added primarily to increase the strength and stiffness of the matrix. Composites are versatile, used for both structural applications and components, in all aircraft and spacecraft, from hot air balloon gondolas and gliders, to passenger airliners, fighter planes and the Space Shuttle. 
Applications range from complete airplanes such as the Beech Starship, to wing assemblies, helicopter rotor blades, propellers, seats and instrument enclosures.

\section{3benifits Of Composites In Aerospace}

1. Weight reduction - savings, overall, in the range $20 \%-50 \%$ are often quoted.

2. Mechanical properties can be tailored by 'lay-up' design, or ply - design, with tapering thicknesses of composite resorting to ply drop - offs.

3. Thermal stability of composites means they don't expand/contract excessively with change in temperature (for example a $90^{\circ} \mathrm{F}$ runway too $-67^{\circ} \mathrm{F}$ at 35,000 feet in a matter of minutes).

\subsection{Classification Of Composites}

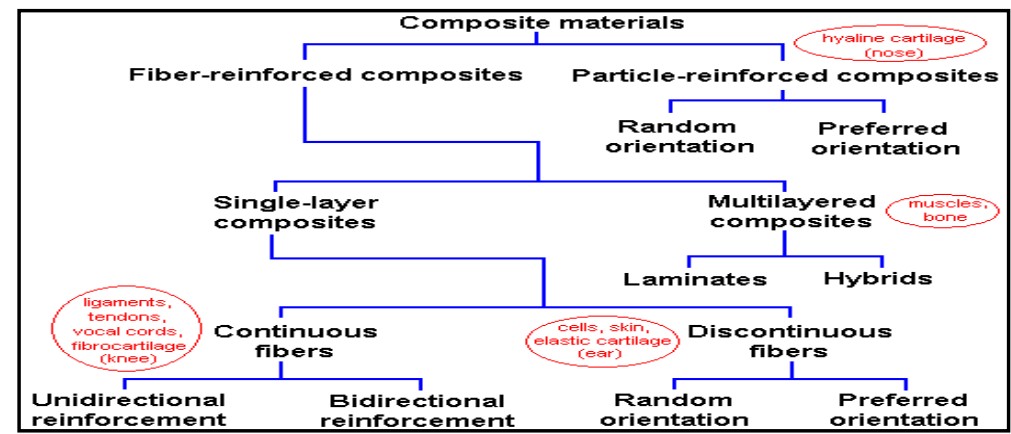

Fig 1.1 Classifications of Composites

2.5 Materials:-

2.5.1 Types Of Fibers:

2.5.2 Carbon Fiber:

Carbon fiber is produced by two different methods known as PAN or Pitch. Thousands of thin strands of carbon (of the order of 5-8 microns) are produced and combined to create a tow. that are used in the composite structure. Standard grade carbon fibers have a good combination of strength with stiffness. With a specific modulus of 92, over 3 times that of metal (Steel and aluminum are both the same) carbon fiber / epoxy laminates are finding increasing application. Typically UTS 1.5 GPa Modulus (Ex) $130 \mathrm{GPa}$ Density $1.6 \mathrm{~g} / \mathrm{cc}$.

\subsubsection{Aramid Fibers:}

This was the first organic fiber to be used as reinforcement in advanced composites. Today this fiber is used in various structural parts of reinforced plastics, such as, ballistics, tires, ropes, cables The density of aramid is $0.052 \mathrm{lb} / \mathrm{in} 3(1.44 \mathrm{gm} / \mathrm{cm} 3)$.This is about $40 \%$ lower than glass and about $20 \%$ lower than commonly used carbon. Aramids do not melt and they decompose at about $900^{\circ} \mathrm{F}\left(500^{\circ} \mathrm{C}\right)$. Tensile strength of yarn, measured in twisted configuration, can be varied from $500-600 \mathrm{ksi}(3.4-4.1 \mathrm{GPa})$ by choosing different types of aramids. Aramid fibers, being aromatic polyamide polymers, have high thermal stability and dielectric and chemical properties Aramid is used, in fabric or composite form, to achieve ballistic protection for humans, armored tanks, military aircraft, and so on.

\subsubsection{Glass Fiber:}

Glass in the forms used in commerce has been produced by many cultures since the early Etruscan civilization. Due to the high quantity of commercial applications for glass products, there are many product forms available. Perhaps the most versatile fiber type to produce glass product forms is "E" glass. "E" glass is identified as such for electrical applications. This type or grade of glass fabric has eight or more standardized thicknesses available. These range from 1.4 to 13 mils $(0.26$ to $0.325 \mathrm{~mm})$. This facilitates very thin product forms. The "S" glasses are identified as such to signify high strength. Although there isomer "E" roving products, as to yields, available, this has not noticeably restricted the use of S-2 type roving products or roving for unidirectional tape. S-2 type roving's are available in yields of 250, 750, and1250 yards per lb (500, 1500, and $2500 \mathrm{~m} / \mathrm{kg}$ ). 


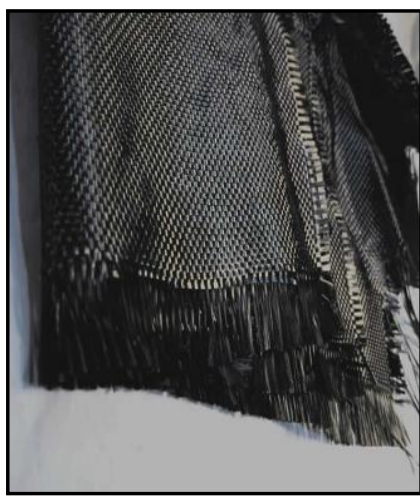

Fig 2.1 Carbon Fiber Fig

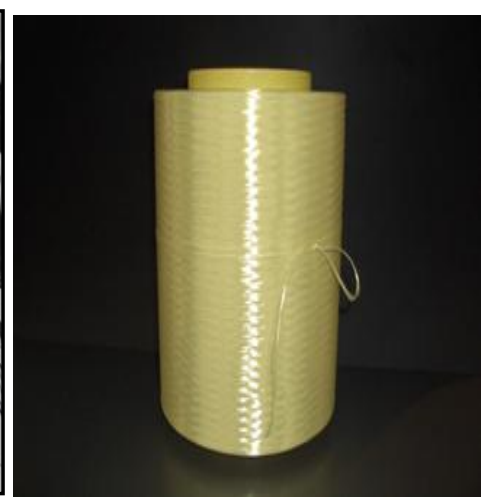

Fig 2.2 Aramid Fiber

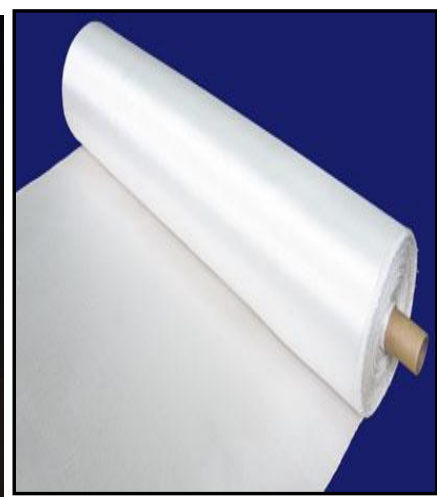

Fig 2.3 Glass fiber

\section{Design}

Design requirements are set by prior design trade studies. Concepts are developed to meet requirements. Design analysis frequently Points towards new concepts and technologies, which can initiate a whole new design effort.

\subsection{Designing Of Die Block}

A die is a specialized tool used in manufacturing industries to cut or shape material mostly using a press. Design of die block depends upon work piece size and thickness.

- Overall dimensions of the die block will be determined by the minimum wall thickness of the die required for strength.

- The minimum thickness of the die should not be less than $10 \mathrm{~mm}$ based on our press requirement.

- Design Requirements:1.paper sketch of Design of die and final product 2,AutoCAD software

3,Skills to Design 4,three dimensional visualization.

\subsection{Cad Designing:}

AutoCAD is a high end CAD (Computer Aided Drafting) Program. Where our idea gets into 2D and 3D. Firstly, why we choose AutoCAD because, it's easy to understand, well Known to engineers and easy to draw and present. Coming to Design of Die, the every part of die is been mentioned in drawing with measurement for effective understanding to Mold maker.
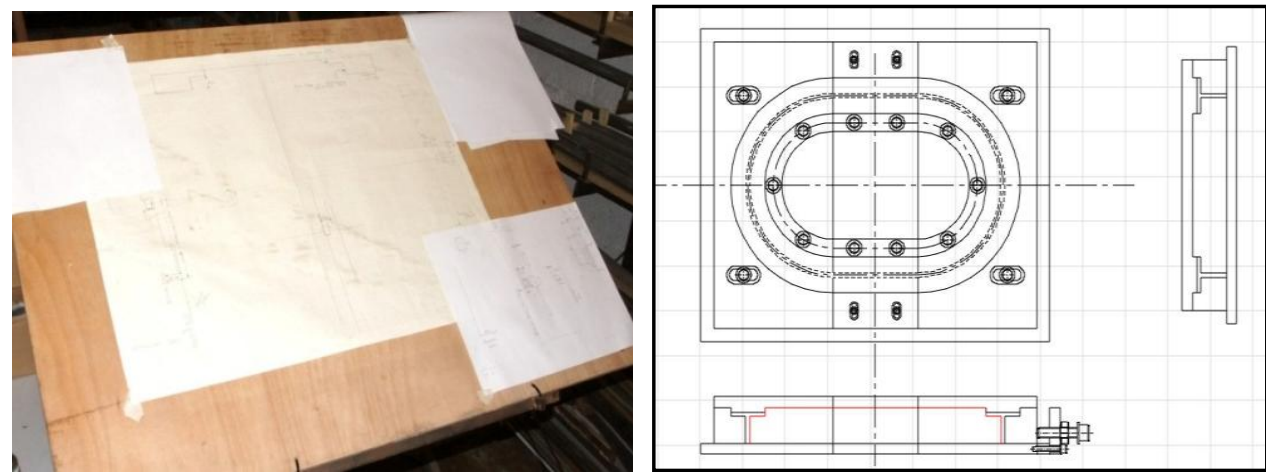

Fig 3.1 paper sketch of Design of die and final product Fig 3.2Match die Mold Design with two side views

\subsection{DETAIL DESIGNING:}




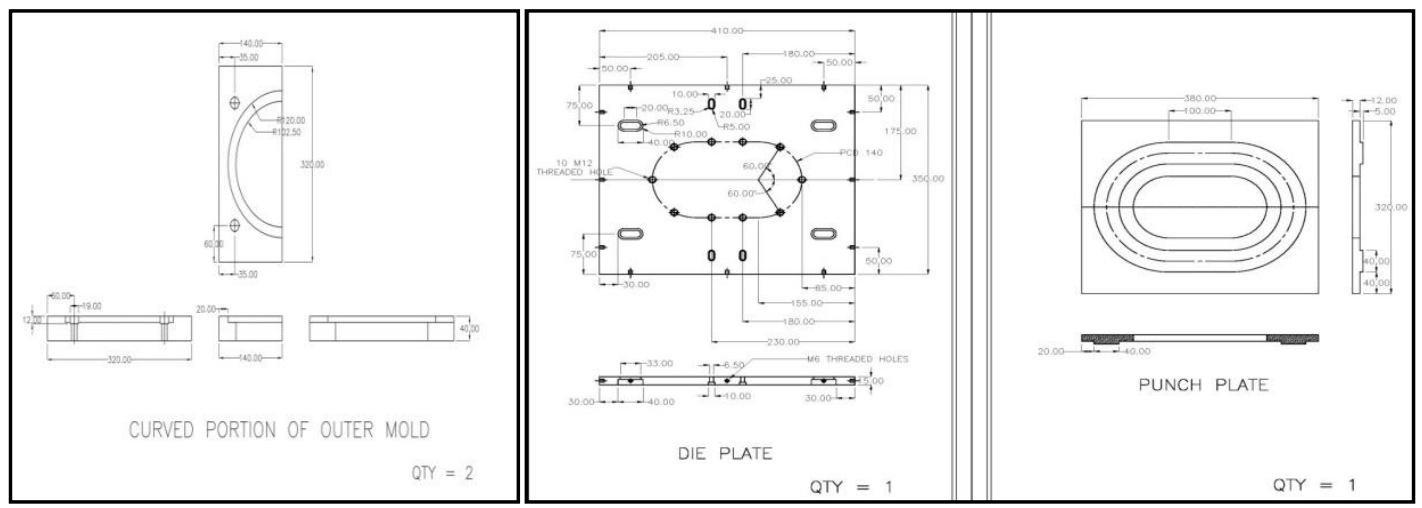

Fig 3.3 Curved portion of outer mold

Fig 3.4 Die plate and punch plate Measurements
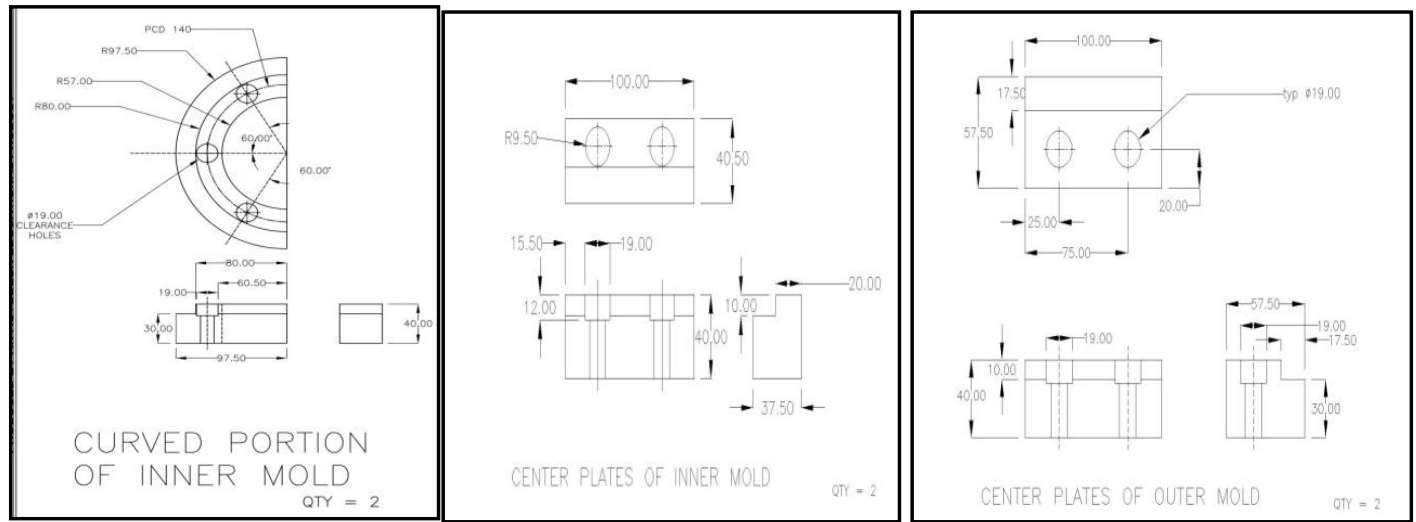

Fig 3.5 Curved portion of inner mold, Fig 3.6 L-N bolt size indication of inner mold, Fig 3.7 L-N bolt size indication of Outer mold

\subsection{Matched Die Molding For Frp}

3.1 Matched Die Molding Of Fiber Reinforced Plastic

Lightweight glass fiber reinforced plastic products are produced in matched dies by combining fibrous reinforcing materials, such as glass fibers, with a foam able unsaturated polyester resin composition.

\subsection{Mild Stell (En-18) Die}

As per the measurements the EN-18 steel plates are taken and following operation are done to get the final mold of aircraft window frame.

\subsubsection{List Of Operations Involved In Making Die}

1,Cutting 2,grinding 3,turning 4,milling 5,Sheet through 6,CNC Milling 7,CNC wire cut 8,Tig welding 9,Surface Grinding 10,Slot Grooving 11,Drilling 12,Tapping 

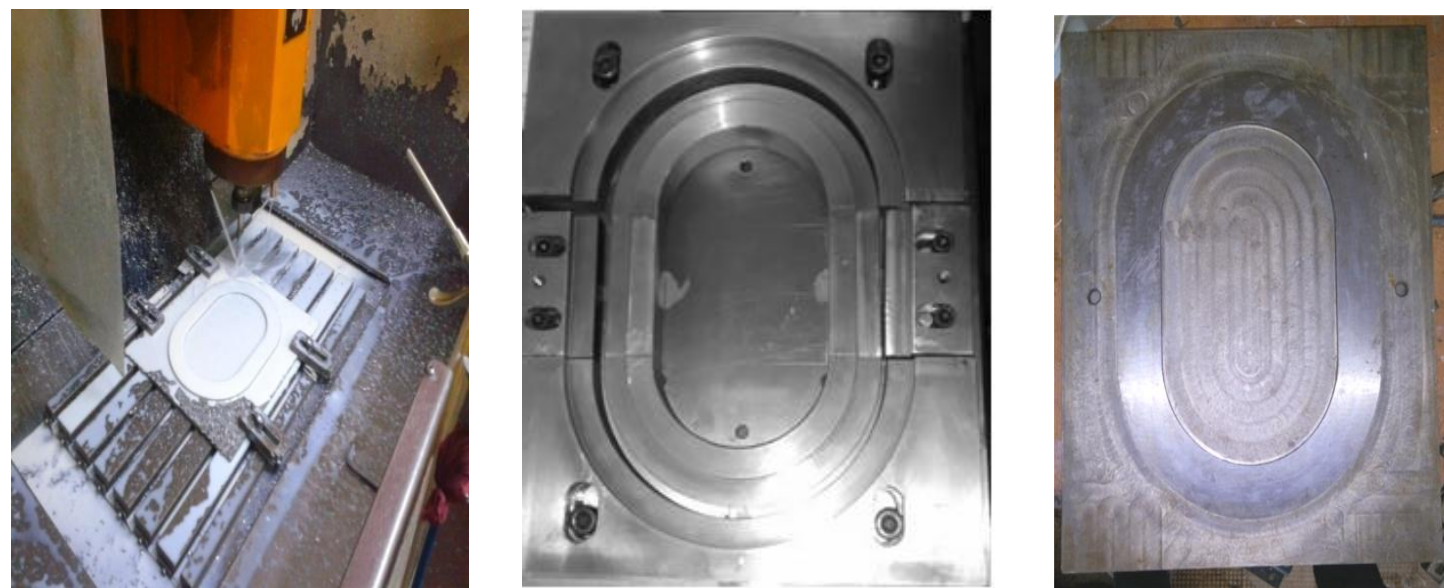

Fig 3.1 CNC Milling of Punch plate, Fig 3.3 Final Assemble of mold, Fig 3.4 punch plate

\section{Fabrication}

Firstly, Knowing Fabrication techniques are most important in Composite Fabrication. By knowing different Fabrication Techniques, the Process to make window Frame is discussed.

\subsection{Fabrication Techniques}

There are numerous methods for fabricating composite components. Some methods have been borrowed (injection molding, for example), but many were developed to meet specific design or manufacturing challenges..

\subsection{E-Glass Fabric}

E-Glass or electrical grade glass was originally developed for standoff insulators for electrical wiring. It was later found to have excellent fiber forming capabilities and is now used almost exclusively as the reinforcing phase in the material commonly known as fiberglass.

\subsubsection{Technical Specifications}
1. Nomenclature
13mil E-GLASS FABRIC
0.36
2. Thickness, mm
$40 "$
3. Width, inch
4 Harness
3. Weave
Warp, Threads/inch: 48
4. Construction
Weft, Threads/inch: $\quad 36$
5. Weight per Sq.mtr $\quad: \quad 455.400 \mathrm{gms}$
6. Breaking Strength per $50 \mathrm{~mm}$
$383.000 \mathrm{Kgs}$
Warp
$258.000 \mathrm{Kgs}$

\subsubsection{Acceptance Test Procedure}

Breaking Strength:

- The breaking strength of the fabric shall be inspected as per ASTM D1682.

- 3 specimens of Warp and 3 specimens of weft shall be tested.

- The acceptance value shall be Warp $191 \mathrm{Kg} / \mathrm{inch}$ and Weft $129 \mathrm{Kg} / \mathrm{inch}$.

Cut the samples of fabric as per ASTM standards and tested, accepted with an accurate result.

\subsubsection{Technical Specifications}

\section{Lapox L-12}

Epoxide equivalent

Epoxy value

\section{Hardener K-6}

Visual appearance

Refractive index at $25^{\circ} \mathrm{C}$
Pale yellow liquid

$1.4940-1.5000$

\subsection{Fabrication Of Aircraft Window Frame}

A single layer of a laminated composite material is generally referred to as a ply or laminate. It usually contains a single layer of reinforcement, unidirectional or multidirectional. Properties and orientation of the laminate in a laminate are chosen to meet the laminate design requirements. Properties of a laminate may be predicted by knowing the properties of its constituent laminate. 
Step-1: The fabric is laid on work bench covered with polythene sheet Marking is taken up with mold dimensions $83.5 * 45$ strip and ellipse dimensions of radius $300 * 200$ respectively. and the sequence of vertical strip is increased by 0.1 for every layup.
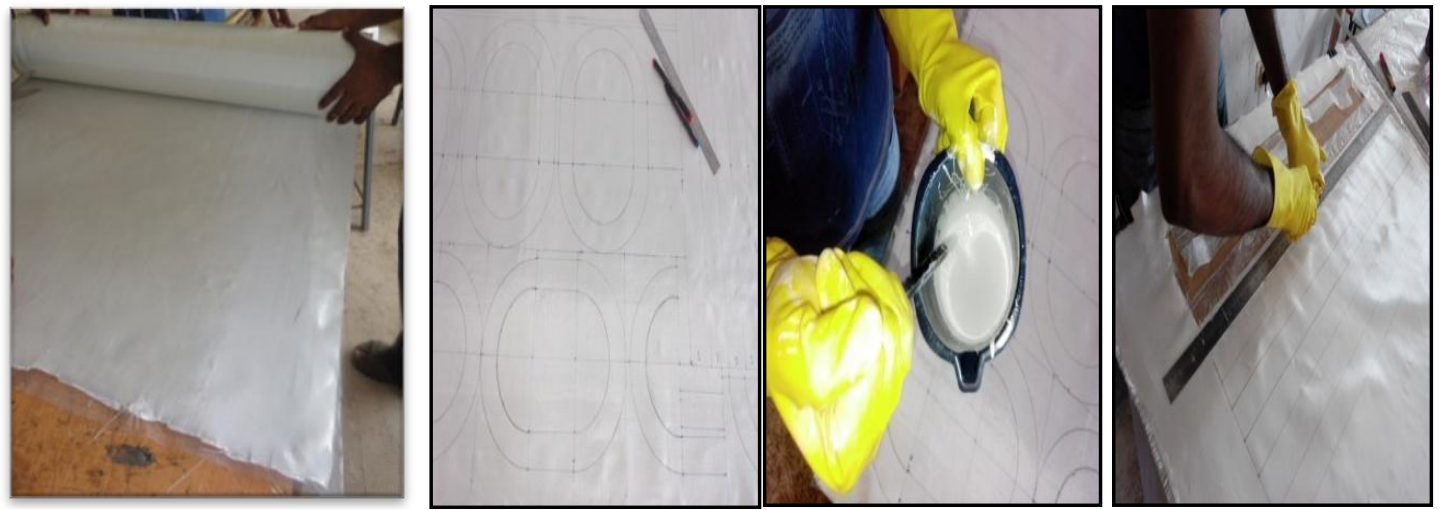

Fig 1: Glass fiber, fig 2: Marking window as per dim, fig 3: Matrix Mixing, fig 4: Cutting the Plies
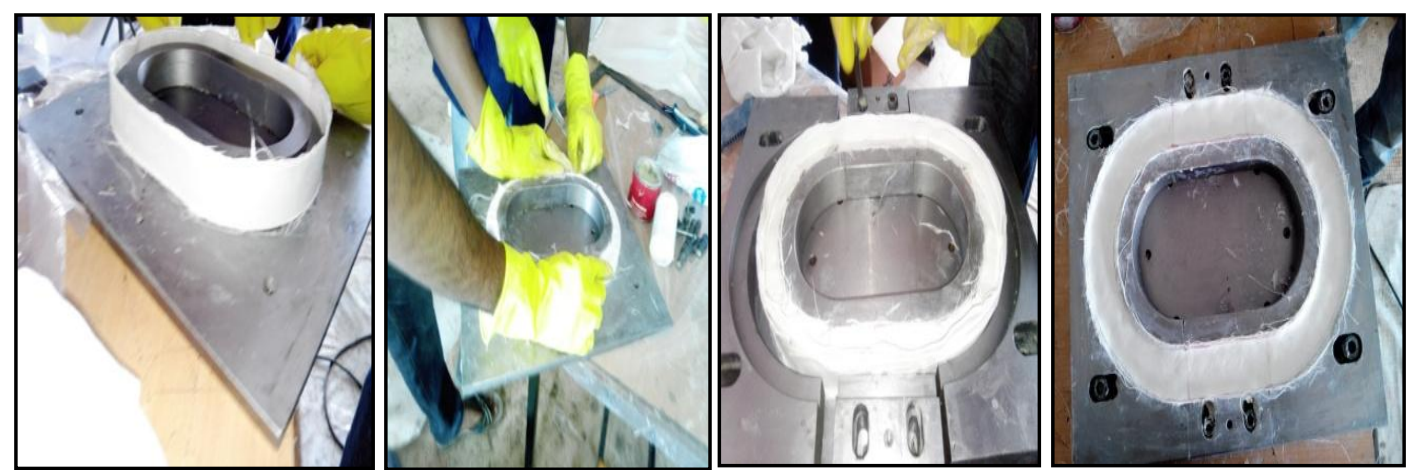

Fig 5: Folding Of Ply fig 6: Placing the First Ply fig 7: Assembling Die fig 8: Final View Before Curing

Step-1: The fabric is laid on work bench covered with polythene sheet Marking is taken up with mold dimensions $83.5 * 45$ strip and ellipse dimensions of radius $300 * 200$ respectively. and the sequence of vertical strip is increased by 0.1 for every layup.

Step-2: Matrix is weighed as per specification of fabric that is $76 \mathrm{gms}$ for 10 plies, pigment of $5 \%$ for color surface typically white and harden is added in the ration of 1:10.

Step-3: An optional sacrificial layer (Surface mat) is laid up on the mold surface. This layer is usually a fiberglass fabric made with the same resin system as the composite laminate. The sacrificial layer protects the laminate from surface abrasion and surface irregularities during manufacturing.Cutting Plies in required size.Step-4: Firstly, Inner mold is fitted and one by one plies are Layed to the mold

Step 5: Assembling and fixing of die .

Step 6: Finally mold is closed and kept in Hydraulic press

The process of polymerization is called "curing", and can be controlled through temperature and choice of resin and hardener compounds; the process can take minutes to hours. Some formulations benefit from heating externally supplied during the cure period, whereas others simply require time, and cure on account of mild increase in internal temperatures on account of chemical reactions. 


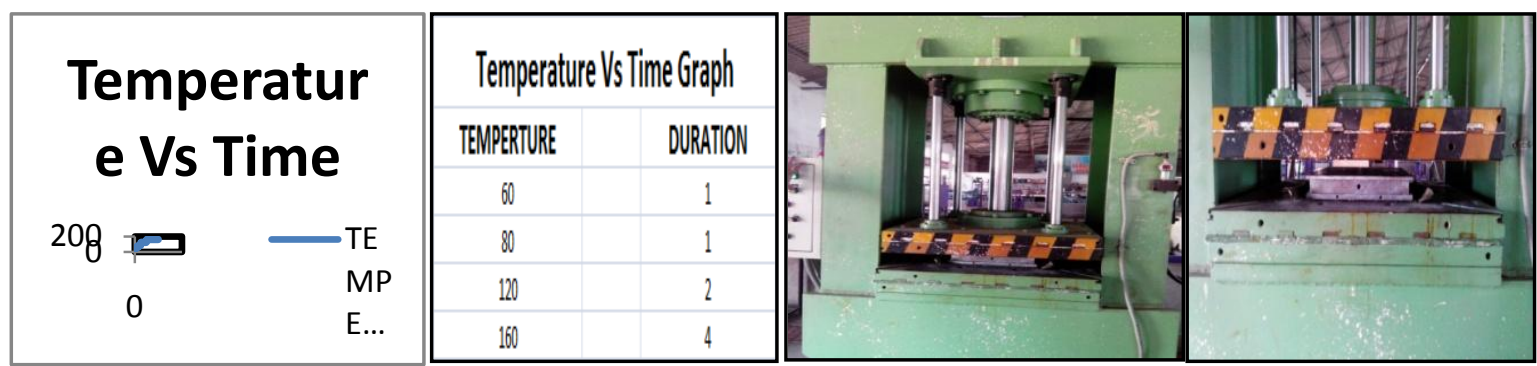

Graph 1: Curing cycle Table.1: Temperature vs. time Fig: 16 Hydraulic pres $\quad$ Fig: 17 Curing In the first stage of cure cycle temperature up to $60^{\circ} \mathrm{C}$ and dwelling at this temperature for nearly 60 minutes. At the end of the temperature dwell, the oven temperature is increased to the actual curing temperature for the resin that is $80^{\circ} \mathrm{C}$. After setting the oven temperature to $80^{\circ} \mathrm{C}$ the part temperature slightly increases to $120^{\circ} \mathrm{C}$, and later $160^{\circ} \mathrm{C}$ The temperature is maintained for 4 hours or more, until a pre-determined level of cure has occurred.

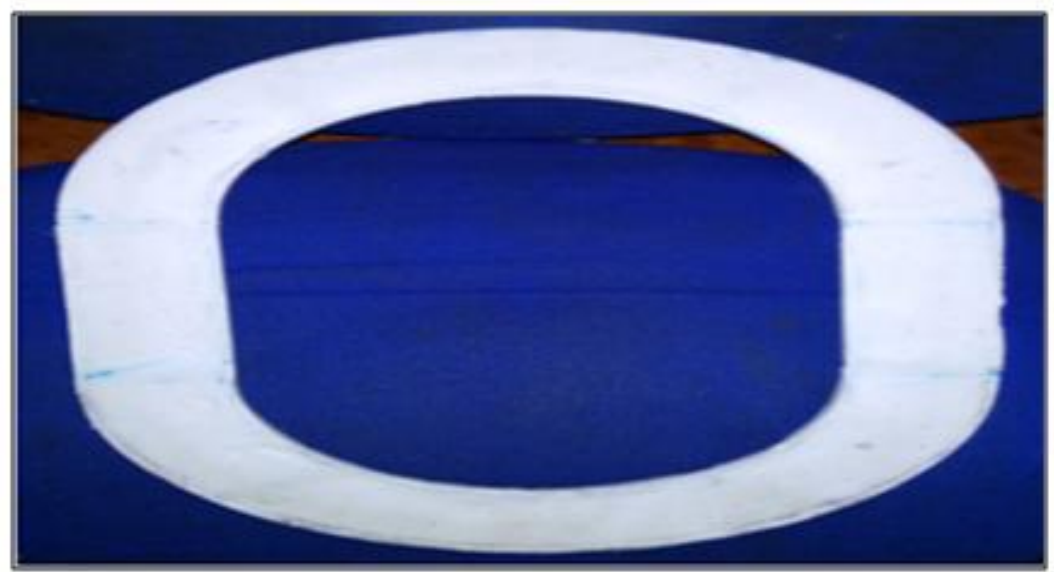

Fig 4.18 Final Component

\subsection{Vibration Testing Mechine}

\section{Testing \& Analysis}

Vibration testing is done to introduce a forcing function into a structure, usually with the use of a vibration test shaker or vibration testing machine. These induced vibrations, vibration tests, or shaker tests are used in the laboratory or production floor for a variety of things, including qualifying products during design, meeting standards, regulatory qualifications, fatigue testing, screening products, and evaluating performance.

\subsection{1vtm In Aerospace}

Manufacturers of modern airplanes face challenges such as volatile weather conditions, temperature, atmospheric pressure, and heavy structural loads. Spacecraft design requires rigorous testing to meet environmental challenges, weight specifications, and flight launch issues. As a result, engineers need to produce aerospace components that are safeguarded, enduring, tenacious, and economical.

\subsubsection{Dynamic Measurement In The Aerospace Industry}

Aerospace ground vibration tests and flutter tests often require electro dynamic shaker These vibration exciters are available in a large range of sizes from very portable models with relatively high force to models that are capable of several hundred pounds of force.

\subsection{Random Vibration}

A measurement of the acceleration spectral density (ASD) is the usual way to specify random vibration. The root mean square acceleration $\left(\mathrm{G}_{\mathrm{rms}}\right)$ is the square root of the area under the ASD curve in the frequency domain. The $\mathrm{G}_{\mathrm{rms}}$ value is typically used to express the overall energy of a particular random vibration event and is a statistical value used in mechanical engineering for structural design and analysis purposes. 
While the term power spectral density (PSD) is commonly used to specify a random vibration event, ASD is more appropriate when acceleration is being measured and used in structural analysis and testing.

\subsubsection{Electro Dynamic Vibration Mechine (Shaker)}

Equipment designed to generate vibrations.

Vibration frequency: 20 to $2000 \mathrm{~Hz}$ (generates 20 to 2,000 vibrations per second.)

\subsection{Procedural Test Setup Of Window Frame}

Step 1: Firstly, drilling is done as per the measurements took by placing the frame on Vertical Table.

Step 2: Window frame is fitted to vertical table with L-N bolts tightly.

Step 3: Placing the Sensors as per instructions.

Step 4: Switch on the machine and initial time is note and Frequency is set.

Step 5: Test notes on Full Band, In Band and peak are obtained

Graph of acceleration spectral density Vs Frequency and power spectral density

Step 6: Response of the Frame is shown with error or without error is checked.
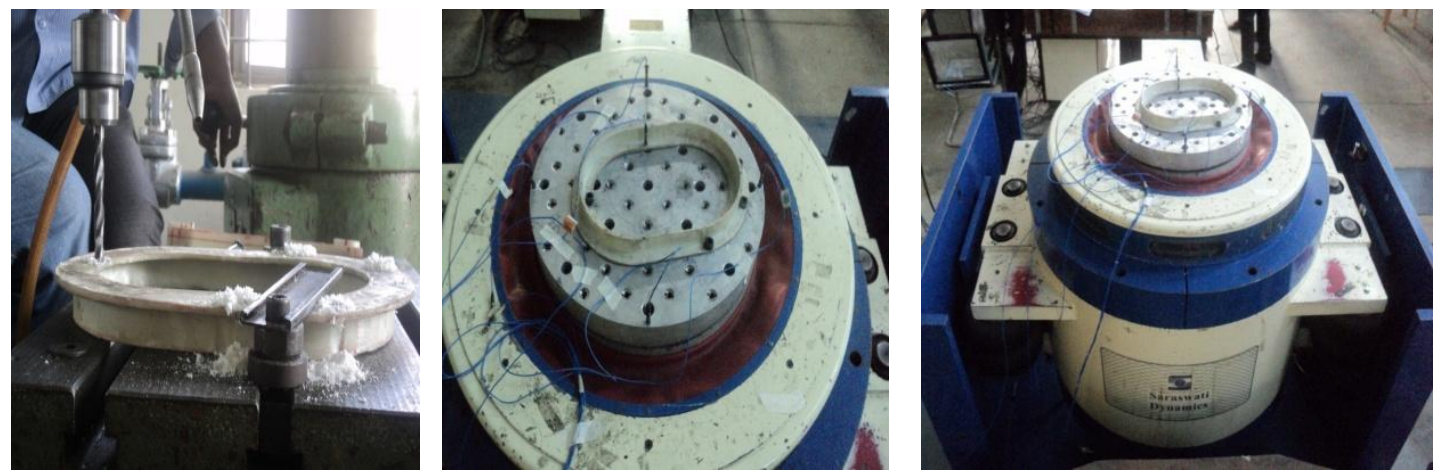

Fig 5.5 8mm Dia drilling Fig 5.8 Placing Sensors to the window Frame Fig 5.9 Final Testing of Window Frame on Vibration testing machine

\subsubsection{Test Values Obatined During Testing}

Testlevelschedule:

Duration Level

1)0:00:05 $25 \%$

2)0:00:05 $\quad 50 \%$

3)0:00:05 $\quad 75 \%$

4)0:01:00 $\quad 100 \%$

5)View Report (prompt)

6)Save Report (prompt)

** Test started Apr 13, 2015 17:54:45, running for 0:01:29

** Current level: 4 , running at $100 \%$ for 0:01:00 of 0:01:00

\section{Measurements: \\ Demand: 4.005 G RMS $1.036 \mathrm{~mm}$ pk-pk \\ Control: 4.007 G RMS $1.542 \mathrm{~mm}$ pk-pk \\ Ch1: 3.892 G RMS Ch1 in-band: 3.879 G RMS \\ Ch2: 3.611 G RMS Ch2 in-band: 3.585 G RMS \\ Ch3: 4.444 G RMS $\quad$ Ch3 in-band: 4.407 G RMS \\ Ch4: 4.105 G RMS Ch4 in-band: 4.079 G RMS \\ Drive voltage: 0.1085 Volts RMS \\ System gain: 0.02706 Volts/G \\ Accelerometer calibration details: \\ Ch1: $5.453 \mathrm{mV} / \mathrm{G} \quad$ (113883, Jan 01, 2015) \\ Ch2: $5.471 \mathrm{mV} / \mathrm{G} \quad(113576$, Jan 01, 2015) \\ Ch3: $4.65 \mathrm{mV} / \mathrm{G} \quad(113578$, Jan 01,2014$)$ \\ Ch4: $4.94 \mathrm{mV} / \mathrm{G} \quad$ (100677, Jan 01, 2015)}

International Conference on Recent Innovations in Civil \& Mechanical Engineering 
Test notes: none

Input measurements:

\begin{tabular}{lllll} 
Channel & \multicolumn{2}{c}{ Full-band RMS In-band RMS Peak } & Kurtosis \\
C1 & 3.892 G RMS & 3.879 G RMS & 11.79 G peak & 3.02 \\
C2 & 3.611 G RMS & 3.585 G RMS & 9.98 G peak & 2.97 \\
C3 & 4.444 G RMS & 4.407 G RMS & 13.15 G peak & 3.03 \\
C4 & 4.105 G RMS & 4.079 G RMS & 11.34 G peak & 2.95 \\
R1 & 6.877 G RMS & 6.836 G RMS & 21.99 G peak & 2.92 \\
Response & & &
\end{tabular}
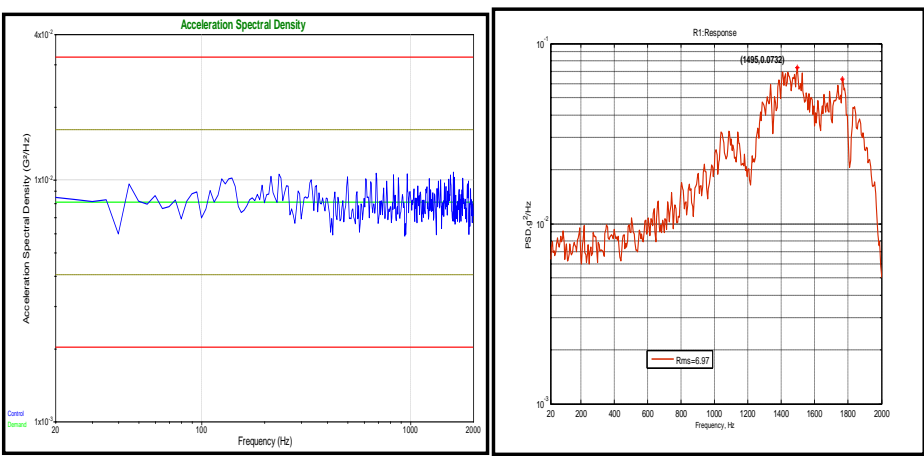

Graph 5.1: ASD Vs Frequency, Graph 5.2: PSD Vs Frequency, Graph 5.3: Comparison of test rest and fem result

\subsection{Unidi Rectional Tensile Test}

A tensile test, also known as tension test, is probably the most fundamental type of mechanical test you can perform on material. Tensile tests are simple, relatively inexpensive, and fully standardized. By pulling on something, you will very quickly determine how the material will react to forces being applied in tension. As the material is being pulled, you will find its strength along with how much it will elongate.

We keep increasing the weight (often called the load or force) while at the same time measuring the change in length of the sample.

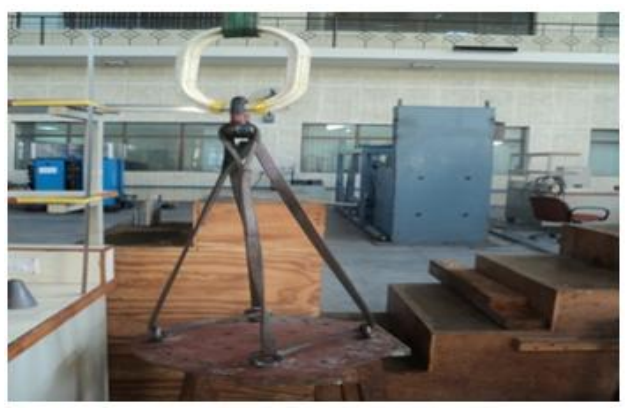

Fig 5.10 Initial fixing,

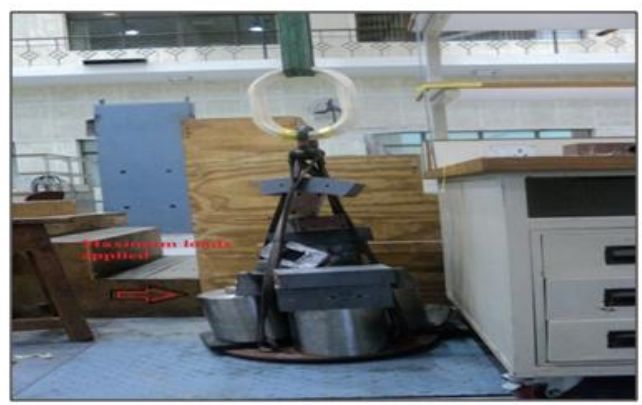

Fig 5.11 Adding weights

Step1: we have a way to hang one end of some material from a solid point that does not move, then can hang weights on the other end. For that to add one by one weight, we net to place weighing tray so that as per the requirement we can add weights

Step 2: Measure the change in length while adding weight until the part begins to stretch and finally breaks. Here it is observed that by adding weights, there is some deflection i.e., and deformation of the Frame, so we can conclude that its can resist much loads.

\subsection{Tensile Test Analysis}

Firstly, we will be design the frame in solid works software and the model is exported to NX Nast ran software for analysis Now we define the material properties of the model. The material used for the window frame is being a composite material; we define the ply sequence and the number of ply's and their orientation. 

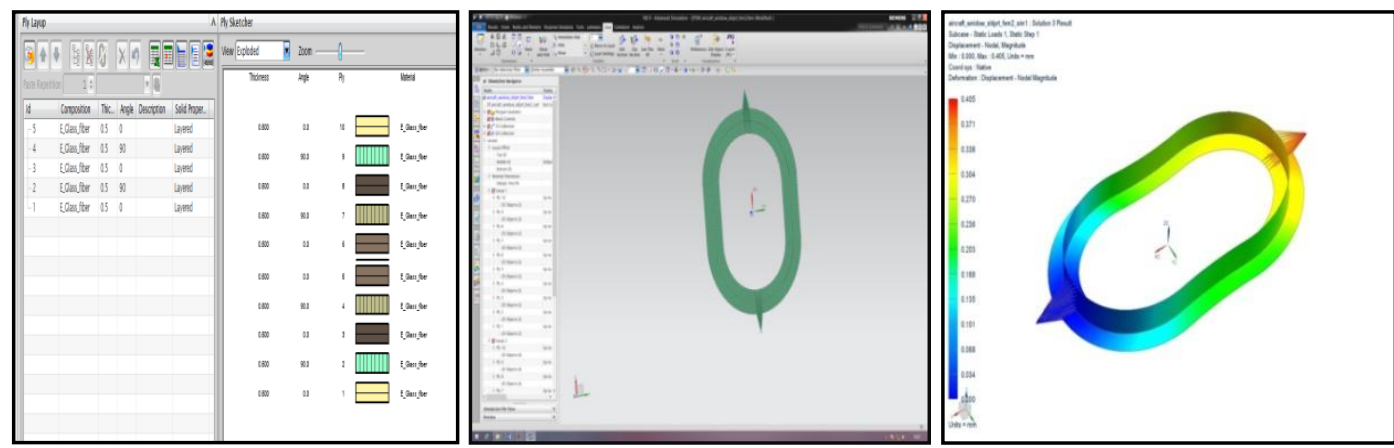

Fig 5.12 Ply orientation Fig 5.13 Nast ran Interface Fig 5.14 Deformation due to loading

This is an unidirectional tensile test, so we constraint one end of the frame by taking a node in space and selecting a few nodes in the frame. The constraint is given to the node in space ( all degree of freedom $\mathrm{DOF}=0)$

\subsection{Loading And Unloading Graph Of Tensile Test}
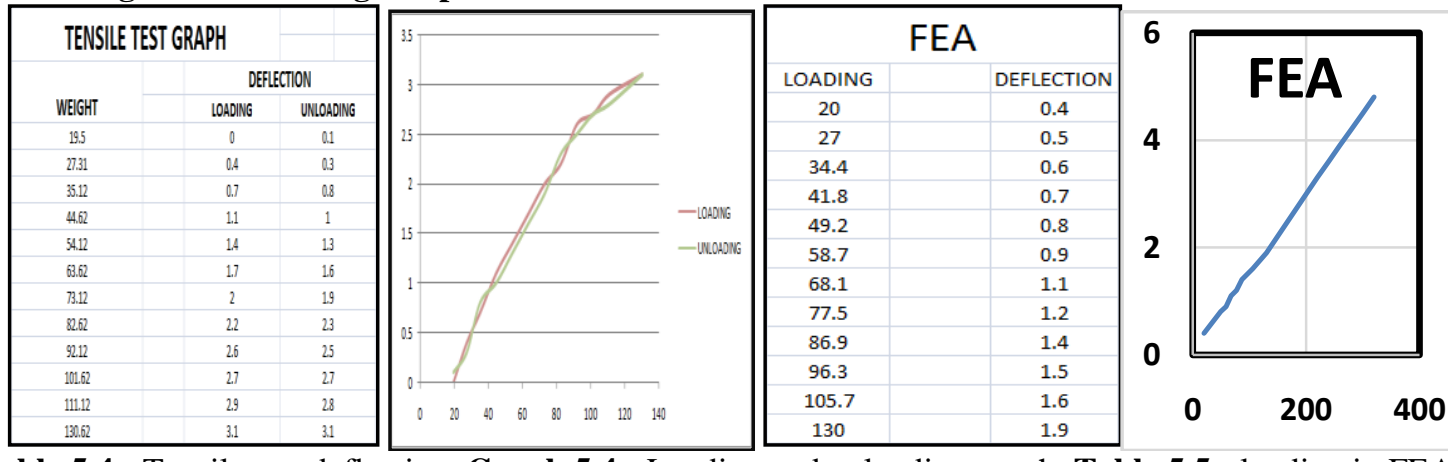

Table 5.4: Tensile test deflection, Graph 5.4: Loading and unloading graph, Table 5.5: loading in FEA of tensile test, Graph 5.5: FEA Graph

\section{Conclusion}

Various Applications of Fiber Reinforced Polymer Matrix Composites For Aerospace Structures have been studied with angled ply construction of $0^{\circ}$ and $0^{\circ} / 90^{\circ}$ orientation composite laminates were fabricated by Match-Die Mold technique. Composites made of E-glass can be replace many metallic components because of their higher specific strength and specific module utilized as liners in nozzles because of their ablative characteristic.

Tailor ability of fiber volume fraction, leads to variation of mechanical properties. In this project we compared the experimental and analytical results. The results are approximately nearby. Therefore, we conclude that the project is valid. Overall Design, Development and testing of composite window frame of aircraft with 50\% less weight compared to normal aluminum frames, Maximum improved strength and less cost of production.

\section{References}

[1]. David Royalance "Introduction to composite material”, Published in composite sci.and technology, March 2000

[2]. An Introduction to the machanics of solids" by S.H.Crandall, N.C. Dahal, and T.J.Lardner

[3]. Aircraft structure for Engineering students"by T.H.G.Megson

[4]. Airframe structure Design" by Michael CY Niu

[5]. Buchanan,G.R., Mechanics of Material, HRW Inc., New Yourk, 1988

[6]. Ugural, A.C. and Fenster, S.K., Advanced strength and Applied Elasticity, $3^{\text {rd }}$ ed. Prentice Hall, Englewood Cliffs, NJ,1995

[7]. Swanson, S.R., Introduction to Design and Analysis With Advanced Composite Material, Prentice Hall,Englewood Cliff,NJ,1997

[8]. Lubin, Hand book of composites, Van Nostarnd, New York, 1982

[9]. Milton, G.W. University of Utah, the theory of composites.

[10]. Preliminary Design Composite Materials and structures (PDCMS) 